\title{
Pediatric Oral/Maxillofacial Soft Tissue Sarcomas: A Clinicopathologic Report of Four Cases
}

\author{
Joel C. Thompson ${ }^{a}$ Gary M. Woods ${ }^{b}$ Michael A. Arnold ${ }^{c, f}$ \\ Charles Elmaraghyg, h Samir B. Kahwash ${ }^{c, f} \quad$ Timothy P. Cripe ${ }^{a, d, e}$ \\ Bhuvana A. Setty ${ }^{a}$ e \\ ${ }^{a}$ Division of Pediatric Hematology/Oncology/BMT, Nationwide Children's Hospital, \\ Columbus, Ohio, USA; ${ }^{b}$ Division of Pediatric Hematology/Oncology, Children's Hospital of

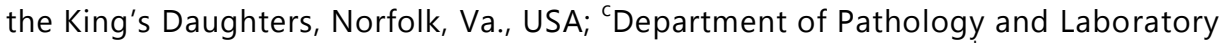 \\ Medicine, Nationwide Children's Hospital, Columbus, Ohio, USA; ${ }^{d}$ Center for Childhood \\ Cancer and Blood Disorders, Nationwide Children's Hospital, Columbus, Ohio, USA; \\ ${ }^{\mathrm{e}}$ Department of Pediatrics, The Ohio State University, Columbus, Ohio, USA; ${ }^{\mathrm{f}}$ Department \\ of Pathology, The Ohio State University, Columbus, Ohio, USA; ${ }^{9}$ Department of Pediatric \\ Otolaryngology, Nationwide Children's Hospital, Columbus, Ohio, USA; ' ${ }^{\text {Department of }}$ \\ Otolaryngology, The Ohio State University, Columbus, Ohio, USA
}

\section{Keywords}

Soft tissue sarcoma $\cdot$ Children $\cdot$ Oral/maxillofacial region

\begin{abstract}
Pediatric soft tissue sarcomas of the oral/maxillofacial region are rare neoplasms that present significant difficulty with respect to treatment and local control measures. We report four cases of pediatric oral/maxillofacial soft tissue sarcomas from our tertiary care pediatric hospital and emphasize the rarity of these malignancies and the challenges encountered in treating these lesions, and suggest areas for further research. We conclude that multimodal therapy and interdisciplinary cooperation are paramount to successful management of these lesions.




\section{Case Reports in Oncology}

\section{Introduction}

Sarcomas are a heterogeneous group of malignancies that are generally identified as arising from mesenchyme-derived tissue [1]. Soft tissue sarcoma (STS) account for only about $12 \%$ of all pediatric head and neck cancers, with a small minority in the oral/ maxillofacial (OMF) region [2]. These tumors present significant challenges for local control due to the proximity and radiosensitivity of regional anatomic structures [2]. These challenges highlight the importance of coordination between various medical subspecialists in planning and executing treatment and local disease control measures. With a multidisciplinary and multimodal approach to management and local control, preservation of function has become a realistic goal of therapy [3].

Our search revealed no published case series that offer a synthesized view of their diagnosis, pathology, treatment, and outcomes. We report four pediatric cases of STS involving the OMF region, highlighting difficulties inherent in managing these lesions, the needs for multimodal therapy and improved risk stratification strategies.

\section{Methods}

The tumor registry at Nationwide Children's Hospital was screened for cases of STS occurring in the OMF region from 2000 to 2015 in accordance with a protocol approved by the Institutional Review Board. Patients with primary lesions in other head and neck sites were excluded.

\section{Case 1}

A 2-year-old Caucasian boy presented with a right upper lip mass and ipsilateral cervical lymphadenopathy. Biopsy of primary site and lymph node excisional biopsy were followed by gross total surgical resection. Pathologic examination showed a tumor composed of solid nests and sheets of monotonous, small malignant cells with cytologic features suggestive of rhabdomyosarcoma (RMS). Mitotic figures and karyorrhectic tumor cells were frequent, and several areas of geographic necrosis were present. Immunohistochemical staining showed diffuse desmin reactivity in the tumor cytoplasm, and myogenin reactivity in more than $95 \%$ of tumor nuclei, supporting the diagnosis of alveolar RMS (fig. 1a, b). There were no sites of metastatic disease on pre-therapy evaluation, and the patient was categorized as clinical group II, stage 1, intermediate risk. He received chemotherapy with vincristine, dactinomycin, and cyclophosphamide (VAC) with radiotherapy for local control (41.4 Gy in 23 fractions). Complete response was seen with no evidence of disease at end-of-therapy evaluation.

Thirteen months after the original diagnosis, a left frontal lobe mass was discovered and resected. This demonstrated similar pathological findings to his original tumor. Molecular studies were performed and demonstrated a fusion of the PAX3 and FOXO1 genes. He received chemotherapy with vincristine, doxorubicin, and cyclophosphamide alternating with ifosfamide and etoposide, and intrathecal chemotherapy. Local control was achieved with 45 Gy radiotherapy in 25 fractions.

Twenty months later, a solitary right leg mass was resected, and pathology confirmed relapsed alveolar RMS. He received cyclophosphamide and topotecan and underwent autol- 


\section{Case Reports in Oncology}

ogous hematopoietic stem cell transplantation with a preparatory regimen of vincristine, melphalan, and thiotepa. He remained in remission for 8 months until he developed right eye swelling and was found to have an orbital mass; this was partially resected and redemonstrated alveolar RMS. He again received radiotherapy (44.6 Gy in 25 fractions). Four months later, he developed a left lung nodule which was biopsied and confirmed disease relapse. He received lung radiation with 10 Gy but ultimately succumbed to his disease 5 weeks later, 46 months from his original diagnosis.

\section{Case 2}

A 13-year-old Caucasian girl presented with a $2 \times 2.5 \times 3 \mathrm{~cm}$ right masseter muscle mass which was completely resected. Pathologic examination showed a tumor composed of small nests of small round cells infiltrating skeletal muscle and adipose tissue. The cells showed scant eosinophilic cytoplasm, with cytologic features suggestive of RMS, similar to Case 1. Immunohistochemical staining confirmed this impression, showing focal desmin reactivity (fig. 1c, d). There was no metastatic disease on staging evaluation. She was diagnosed with alveolar RMS, clinical group II, stage 1, intermediate risk. She received chemotherapy with VAC as well as radiation therapy (41.4 Gy in 23 fractions) and was in remission at the end of therapy. She had a complete response and continues to be in remission at her last follow-up 102 months from her original diagnosis.

\section{Case 3}

A 4-year-old Caucasian girl presented with a $3 \times 2 \mathrm{~cm}$ left-sided maxillary mass, which was partially resected. Pathology demonstrated a variably cellular tumor composed of poorly differentiated round to spindle cells with myxoid stroma. The nuclei showed moderate pleomorphism, and mitotic figures were frequent. Immunohistochemical staining showed strong cytoplasmic desmin reactivity, and myogenin reactivity was seen in less than $50 \%$ of the tumor nuclei, supporting the diagnosis of embryonal RMS (fig. 1e, f). There was no metastatic disease on staging evaluation. She was diagnosed with group III, stage 3, intermediaterisk embryonal RMS. She underwent radiation therapy with a dose of 50.4 Gy in 28 fractions and also received chemotherapy with VAC.

Four months later, she developed a local recurrence in the same area, which was again completely resected. She received additional radiotherapy with $30 \mathrm{~Gy}$ in 15 fractions, as well as further chemotherapy with vincristine and ifosfamide/etoposide. Ten months later, she developed a third local recurrence, for which she underwent a gross total resection, radiation therapy at a dose of $10 \mathrm{~Gy}$, and chemotherapy with topotecan. Eight months later (42 months after primary diagnosis), she developed metastatic disease in her lungs and died due to complications of pneumonia.

\section{Case 4}

A 4-year-old Caucasian boy presented with a rapidly enlarging tongue lesion. Microscopically, sections demonstrated a densely cellular tumor composed of poorly differentiated spindle cells with areas containing epithelial elements (fig. 1g, h). Many dilated and 


\section{Case Reports in Oncology}

branching vascular spaces were present, and focal areas were less cellular with myxoid stroma. Mitotic figures were abundant. Immunohistochemical staining was negative for desmin and myogenin. Pancytokeratin and epithelial membrane antigen stains showed reactivity in many spindle cells, and highlighted the epithelial elements. RT-PCR testing identified a fusion of the SS18 and SSX1 genes, confirming the diagnosis of synovial sarcoma. No evidence of metastatic disease was identified on pre-therapy evaluation. He underwent a gross total resection of the lesion with reconstruction of his tongue using fasciocutaneous left radial forearm free flap. Due to airway safety concerns, a tracheostomy tube was placed at the same time and was subsequently removed 2 weeks later. Radiation therapy after surgical resection was deferred despite narrow negative margins due to concern for associated morbidity. He completed chemotherapy with 6 cycles of ifosfamide and doxorubicin and continues to be disease-free 36 months after his original diagnosis.

\section{Discussion}

We report four cases of STS occurring in the OMF region at a tertiary care pediatric center over a 15-year period. The broad differential diagnosis of lesions in the OMF region is described in table 1. The rarity of STS in this region and the preponderance of RMS noted at our institution are consistent with data from larger epidemiological studies [3]. Pathol ogy showed overlapping poorly differentiated features, demonstrating the importance of immunohistochemistry and molecular testing in confirming the diagnoses. The diagnostic accuracy of fine-needle aspiration cytology for primary diagnosis and recurrences have been reported in tumors of the OMF region with a sensitivity of $96.2 \%$ and specificity of $99.4 \%[4]$.

These four cases highlight several important multidisciplinary aspects of managing these patients, primarily the difficulty associated with local control of malignancies in this region. Cases 1 and 3 endured multiple local and distant recurrences. Case 3, in particular, demonstrates the difficulty of achieving adequate local control. Current recommendations include optimizing surgical resection even at metastatic sites; however, this is generally not feasible with widely metastatic disease.

Radiation therapy, however, is readily utilized for metastatic sites and as well as grossly resected disease with positive margins. With the advent and precision of new technologies, there is an increasing interest in proton beam radiotherapy as it has been shown to have utility in the treatment of head and neck malignancies [5]. The primary advantage is the ability to spare surrounding normal tissues from unintended irradiation. For patients with oropharyngeal cancer, decreased symptoms of dysphagia and xerostomia have been reported [6]. A head-to-head comparison of intensity-modulated photon therapy with intensitymodulated proton therapy is ongoing, and the results from this trial will quantify the clinical benefit to patients from the reduction of dose to nontarget tissues [7]. Fewer than 20\% of RMS are resected with negative margins [8], and radiation therapy has a well-known role in the management of RMS. Coordination between surgeons, oncologists, and radiation oncologists with consideration of modality with least morbidity is of the utmost importance as demonstrated in Case 4.

It is not surprising that the two patients (Cases 1 and 3) who suffered multiple episodes of recurrent disease ultimately succumbed to their disease. Additionally, the three cases with RMS are examples of the heterogeneous outcomes observed in intermediate-risk RMS [8] and highlight the need for better risk stratification methods for these patients. The tumor in 
Case 1 was positive for the $P A X 3 / F O X O 1$ fusion gene product, which is known to be a poor prognostic marker [9]. Yet without integration of $P A X 3 / F O X O 1$ into stratification algorithms, he was considered to have intermediate-risk disease. Preliminary gene expression profiling work in pediatric RMS has been performed [10], and further studies are currently underway attempting to better understand the biological implications for risk stratification in RMS in particular and STS in general [11].

Our four cases represent a large case series of pediatric OMF STS, reinforcing the rarity and the spectrum of these malignancies. Individual pediatric case reports have reported rare OMF STS tumors such as leiomyosarcoma [12], alveolar soft part sarcoma [13], and fibrosarcoma [14]. We highlight the various presentations, approaches to management, and distribution of STS in the OMF region, and challenges faced to achieve satisfactory local control.

\section{Statement of Ethics}

The authors have no ethical conflicts to disclose.

\section{Disclosure Statement}

The authors have no conflict of interest to report.

\section{References}

1 Pappo AS, Parham DM, Rao BN, Lobe TE: Soft tissue sarcomas in children. Semin Surg Oncol 1999;16:121-143.

-2 Huh WW, Fitzgerald N, Mahajan A, et al: Pediatric sarcomas and related tumors of the head and neck. Cancer Treat Rev 2011;37:431-439.

3 Albright JT, Topham AK, Reilly JS: Pediatric head and neck malignancies 2014;128:655-659.

- 4 Daskalopoulou D, Rapidis AD, Maounis N, et al: Fine-needle aspiration cytology in tumors and tumorlike conditions of the oral and maxillofacial region: diagnostic reliability and limitations. Cancer 1997;81:238-252.

5 Holliday EB, Frank SJ: Proton radiation therapy for head and neck cancer: a review of the clinical experience to date. Int J Radiat Oncol Biol Phys 2014;89:292-302.

-6 van de Water TA, Lomax AJ, Bijl HP, et al: Potential benefits of scanned intensity-modulated proton therapy versus advanced photon therapy with regard to sparing of the salivary glands in oropharyngeal cancer. Int J Radiat Oncol Biol Phys 2011;79:1216-1224.

7 Frank SJ: Intensity-Modulated Proton Beam Therapy (IMPT) versus Intensity-Modulated Photon Therapy (IMRT). Available at: https://clinicaltrials.gov/show/NCT01893307. Accessed August 7, 2015.

-8 Meyer WH, Spunt SL: Soft tissue sarcomas of childhood. Cancer Treat Rev 2004;30:269-280.

-9 Hettmer S, Li Z, Billin AN, Barr FG, et al: Rhabdomyosarcoma: current challenges and their implications for developing therapies. Cold Spring Harb Perspect Med 2014;4:a025650.

10 Davicioni E, Anderson JR, Buckley JD, et al: Gene expression profiling for survival prediction in pediatric rhabdomyosarcomas: a report from the children's oncology group. J Clin Oncol 2010;28:1240-1246.

11 Shern JF, Chen L, Chmielecki J, et al: Comprehensive genomic analysis of rhabdomyosarcoma reveals a landscape of alterations affecting a common genetic axis in fusion-positive and fusion-negative tumors. Cancer Discov 2014;4:216-231.

12 Cheng C-Y, Chang K-M, Chang K-W, et al: Rapidly growing mass in mandibular gingiva. J Oral Maxillofac Surg 2004;62:214-217.

13 Castle JT, Goode RK: Alveolar soft part sarcoma of the tongue: report of an unusual pattern in a child. Ann Diagn Pathol 1999;3:315-317.

14 Sato M, Tanaka N, Sato T, et al: Oral and maxillofacial tumours in children: a review. Br J Oral Maxillofac Surg 1997;35:92-95. 


\section{Case Reports in Oncology}

\begin{tabular}{l|l}
\hline Case Rep Oncol 2016;9:447-453 \\
\hline $10.1159 / 000447689$ & $\begin{array}{l}\text { C } 2016 \text { The Author(s). Published by S. Karger AG, Basel } \\
\text { www.karger.com/cro }\end{array}$ \\
\hline
\end{tabular}

Thompson et al.: Pediatric Oral/Maxillofacial Soft Tissue Sarcomas: A Clinicopathologic Report of Four Cases
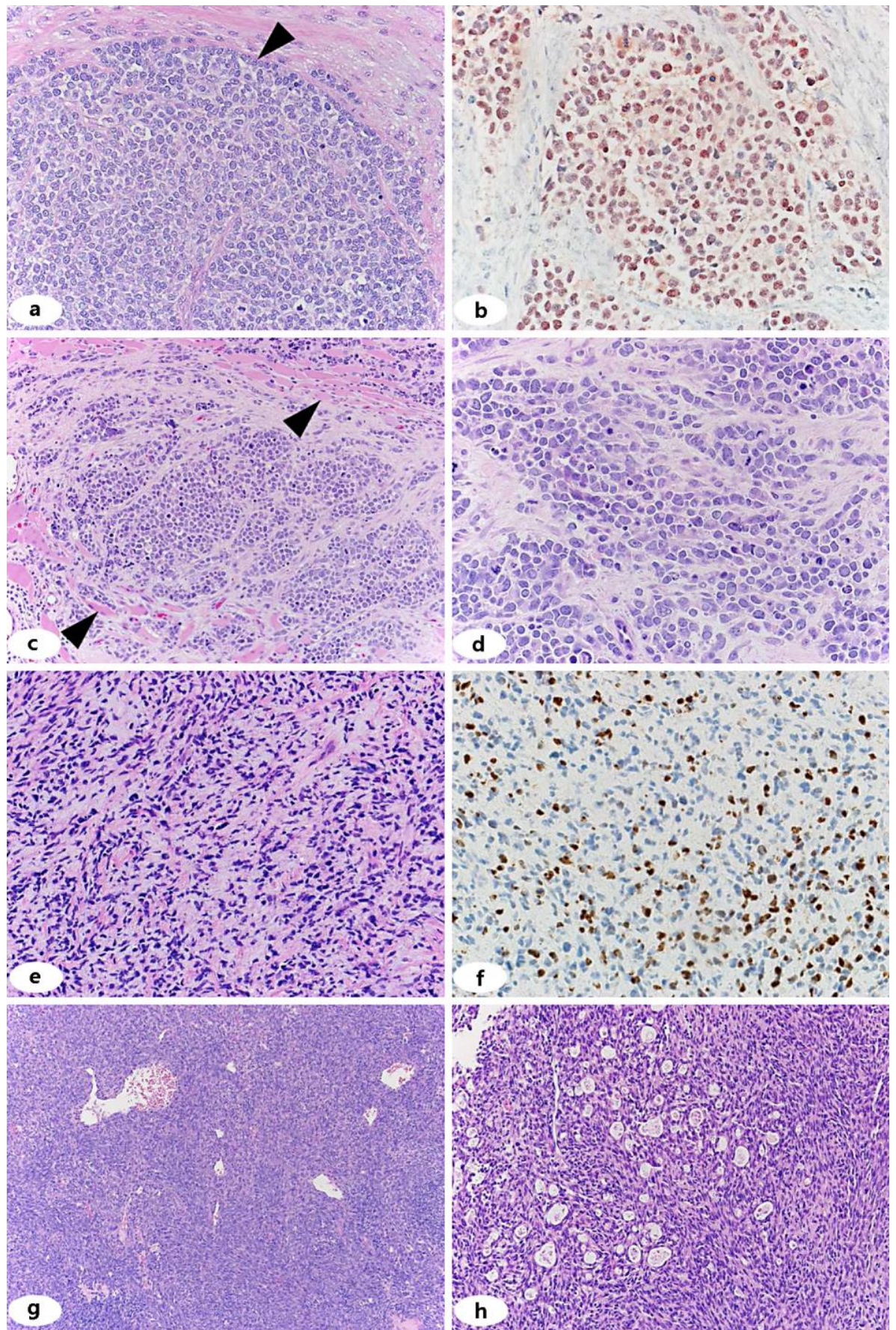


\section{Case Reports in Oncology}

Thompson et al.: Pediatric Oral/Maxillofacial Soft Tissue Sarcomas: A Clinicopathologic Report of Four Cases

Fig. 1. Histologic and immunohistochemical features of OMF sarcomas. Case 1 shows solid nests of tumor cells with round nuclei and scant eosinophilic cytoplasm (a, 40× objective magnification). Linear arrangement of the tumor cells was focally seen at the edges of the nests of tumor cells (a, arrowhead). Immunohistochemical staining for myogenin demonstrated reactivity in nearly all tumor nuclei $(b, 40 \times$ objective magnification). Biopsies of Case 2 show nests of tumor cells infiltrating skeletal muscle (c, arrowheads, 20x objective magnifications). The tumor cells show round nuclei and frequent single cells undergoing mitosis or karyorrhexis (d, 40× objective magnification). Case 3 shows spindle cells in a myxoid matrix and relative nuclear pleomorphism compared with Cases 1 and 2 (e, 40× objective magnification). Myogenin immunohistochemical staining highlights less than half of the tumor nuclei (f, $40 \times$ objective magnification). The tumor cells of Case 4 show spindle cells arranged in short curved fascicles with scattered dilated and branching vascular spaces (g, 10x objective magnification). Focal areas of the tumor demonstrate intermixed epithelial elements ( $h$, $20 \times$ objective magnification).

Table 1. Differential diagnosis of soft tissue masses of the mouth and face in children

\begin{tabular}{|c|c|c|c|}
\hline Congenital & Infectious & Benign & Malignant \\
\hline $\begin{array}{l}\text { Dermoid cyst } \\
\text { Hemangioma } \\
\text { Lymphangioma }\end{array}$ & $\begin{array}{l}\text { Lymphadenitis } \\
\text { Odontogenic infection } \\
\text { Parotitis } \\
\text { Periorbital/orbital cellulitis } \\
\text { Soft tissue cellulitis/abscess }\end{array}$ & $\begin{array}{l}\text { Angiofibroma } \\
\text { Dermoid cyst } \\
\text { Hemangioma } \\
\text { Inclusion cyst } \\
\text { Keloid } \\
\text { Lipoma } \\
\text { Lymphangioma } \\
\text { Neurofibroma } \\
\text { Pilomatrixoma } \\
\text { Squamous cell papilloma }\end{array}$ & $\begin{array}{l}\text { Angiosarcoma } \\
\text { Alveolar soft part sarcoma } \\
\text { Lymphoma (Hodgkin's vs. non-Hodgkin's) } \\
\text { Dermatofibrosarcoma protuberans } \\
\text { Epithelioid sarcoma } \\
\text { Langerhans cell histiocytosis } \\
\text { Malignant fibrous histiocytoma } \\
\text { Malignant peripheral nerve sheath tumor } \\
\text { Neuroblastoma } \\
\text { Rhabdomyosarcoma } \\
\text { Synovial sarcoma } \\
\text { Salivary gland neoplasms } \\
\text { Undifferentiated sarcoma }\end{array}$ \\
\hline
\end{tabular}

